\title{
Цифровая эволюция искусства: социо-культурный анализ в контекстах философии и культуры постмодерна
}

\author{
Л.А. Королева \\ РГПУ им А.И.Герцена, Россия \\ klada69@mail.ru
}

\begin{abstract}
Аннотация. В статье проводится осмысление применения цифровых технологий в искусстве. Проводится анализ предпосылок и связей в процессах интеграции цифровых технологий в искусство. Доказывается, что как сама необходимость использования цифровых технологий, так и развитие инновационных «цифровых» форм искусства обусловлены, во-первых, самой природой творчества, во-вторых, - меняющейся психологией познания и новым сформированным сознанием человека под влиянием социокультурных изменений, в том числе опыта применения цифровых технологий во всех сферах деятельности. В работе предлагается подход к анализу новых форм современного визуального искусства, основанный на исследовании изменений в философии и культуры, начавшихся в рамках развития постмодернизма и происходящих в условиях развития компьютерных технологий. Автор считает необходимым подходить к исследованию проблемы конкуренции традиционного и цифрового искусства, а также синтеза цифровых технологий и традиционных методов в искусстве с позиций понимания постмодернизма как состояния духовной культуры современного постиндустриального общества.
\end{abstract}

Ключевые слова: цифровые технологии, постмодерн, эстетика постмодернизма, медиакультура, нелинейная психология восприятия, концепция иллюзии, философские основы искусства

\section{1. Концепции происхождения и сущности искусства}

Понимание сущности и природы искусства позволяет увидеть закономерность и естественность происходящих в этой сфере изменений в эпоху компьютеризации, в противоположность мнению, что мы наблюдаем «кризис искусства».

Природа искусства сложна, и существует большое количество концепций ее генезиса и подхода к анализу. Это и «естественные» теории происхождения искусства (инстинкт красоты), и божественная природа данного свыше человеку дара, и социальная потребность использования его социальной функции в воспитательной и идеологической целях. Материалистская трактовка смысла и ценности искусства пришла из европейской науки. Платон рассматривал искусство как нравственно-религиозно-политическое воспитание человека. В средние века искусство служило целям укрепления религиозного сознания и образования, а также прославления церкви и правящей 
элиты. В советской России и в СССР и в буржуазном мире XX века искусство призвано было решать соответствующие социальные задачи.

Начало XX века отмечено развитием генетических наук и изучения генезиса различных явлений. В работах П.А. Кропоткина, Дж. Холдейна, В.П. Эфроимсона, Д.С. Лихачева доказывается наследственный характер альтруизма, наращивания гуманизма в развитии духовной жизни человека. Понятие инстинкта одновременно начинает использоваться не только в естественных науках, но и в искусстве [1]. Отсюда некоторый физиологизм в построении теории происхождения искусства, присущий работам ученых того времени.

В понимании феномена искусства основополагающими и объединяющими конкурирующие концепции можно считать идеи П. Флоренского о «неслиянности» и «нераздельности» Человека, Культуры и Искусства [10]. Сейчас становится очевидным, что феномен искусства на уровне индивидуума проистекает из комплекса духовно-биологических потребностостей человека, и предполагает наличие как рационального, так и иррационального начала.

\section{2. Новая социокультурная ситуация - новое сознание - новое искусство}

\section{1. Постмодернистская конвергенция философского и культурологического знания}

Для понимания процессов развития культуры в период активного внедрения цифровых технологий во все сферы человеческой жизни важно определить черты социокультурной ситуации этого времени.

$\mathrm{B}$ середине XX века на смену модерна в Европе приходит постмодерн. Наряду с термином постмодерн используют термин «постмодернизм», под которым обычно понимают культуру эпохи постмодерна. Если в начале термин «постмодернизм» употреблялся для характеристики особого этапа в развитии авангардного искусства, то позднее, на рубеже $70-\mathrm{x}-80$-х г.г. стал применяться к анализу и описанию последнего этапе развития всей культуры, как наиболее адекватное духу времени выражение интеллектуального и эмоционального восприятия эпохи [4].

Такое расширение объясняется синтезом социально-гуманитарного знания, в частности конвергенцией философского и культурологического знания [7].

Термин "постмодернизм" был введен в начале 80-х годов французским философом Франсуа Лиотаром. По Лиотару, постмодернизм - это скептицизм по отношению к концепциям в духе рационалистических традиций, названные им метанарративами [8], в которых прослеживается претензия на объяснительный характер и истинность научного знания.

Понятие постмодернизма вышло за рамки искусствоведения или культурологии, становясь философским, но имеющим различные контексты. При этом постмодернизм в большей степени применяется к анализу духовной культуры, поскольку культура конца XX в. и нач. XXI в. стала той сферой, в которой наиболее революционно выразились изменения в обществе.

Учитывая наличие различных контекстов постмодернизма можно выделить исторический, социальный, философский, психологический, культурологический, эстетический и другие. Для понимания возникновения и развития цифровых видов искусства и оправдания их отнесения к видам искусства, особый интерес представляют такие контексты как психология восприятия мира человеком и психология творчества, философские вопросы познания, медиакультура, эстетические паттерны в обществе.

\section{2. Особенности формирования восприятия мира человеком в условиях среды медиакультуры}

Одна из особенностей постмодерна состоит в формировании массовой культуры. Медиакультура возникла на рубеже XIX-XX вв. как составляющая культуры, как информационная культура, порожденная техническим прогрессом, связанная с трансляцией динамических образов техническими способами записи и передачи изображения и звука. При переходе к постмодерну медиакультура охарактеризовалась такими информационными вызовами 
постиндустриальной эпохи, как «демассификация», «телекратия» и «клип-культура», «виртуальная реальность» и «глобализация».

Медиакультура стала комплексным средством освоения человеком окружающего мира в социальных, интеллектуальных, нравственных, художественных, психологических аспектах. Под влиянием новых знаний и медиа-культуры менялся человек, его способы мышления и восприятия действительности. Термин «демассификация» был впервые употреблен Э. Тоффлером для описания тенденции, характеризующей постиндустриальное общество «третьей волны», главным образом выражавшейся в трансформации информационной структуры и распадом массового общества [6].

В современном информационном обществе массовая культура и «массовое» сознание как мировосприятие формируется благодаря масс-медиа технологиям. На наш взгляд, именно информатизация способствует возникновению многих новых элементов современного мировоззрения, как например, космополитизм в философии культуры. Использование информационных технологий ведет к трансформации форм функционирования культуры и к ее разнообразию. При этом культурные трансформации, новые требования к искусству, новая эстетика, социально-культурные потребности стали основаниями появления множества видов искусств. Это «электронное искусство», «цифровое искусство», видео-арт (в том числе, виджеинг, саунд-арт, медиаинсталляция и медиаскульптура), медиаперформанс (дигитальный перформанс), медиаландшафт (или медиасреда), сетевое искусство (интернет-арт или нет-арт, иногда также вебарт) и др.

Новая модель культуры постмодерна представляет собой совокупность множества направлений. Н.А. Хренов в своей монографии [11, с. 62] показал, что искусство развивается не последовательно, а циклически, и новая картина мира более мозаична, отражается в многообразии художественных эстетических направлений (символизм, футуризм, кубизм, конструктивизм, экспрессионизм, сюрреализм).

\section{3. Особенности новой культуры мышления и новой философии искусства}

Процессы художественного мышления человека, его носителя, очень важны, во-первых, для понимания произошедших в эпоху постмодерна изменений в философии и культуре, а вовторых, - для объяснения широты проникновения цифровых технологий во все в сферы культуры и искусства.

Традиционное искусство в немалой степени было связано с отражением реального мира и человека в нем, но в эпоху, которую назвали постмодерном, изменилось отношение к реальности, которое ранее подчас доходило до преклонения перед ней в реалистическом искусстве. Большое значение для этого поворота имела философия Бергсона. Бергсон критикует односторонность и механическое понимание жизни и развития, присущее характеру познания человека, согласно которому мир состоит из неизменных частей, которые лишь перемещаются в пространстве, а будущее и прошедшее исчисляемы как функция настоящего. В теории Бергсона механистической концепции противопоставлена концепция творческой эволюции [2].

Бергсон вводит «длительность» в основу мира, и мир предлагается рассматривать как динамичный, творческий, непрестанно развивающийся, живой. Он доказывал, что «интеллект способен создавать «отвлечённые» и «общие» понятия, а воспроизвести реальность под силу лишь интуиции, которая, будучи непосредственным переживанием предмета, «внедряется в его интимную сущность» [2].

Теперь художник может делиться интимными переживаниями со зрителями, играть смыслами, уходить от смыслов, делать предметом творчества чувства и настроения, мысли, абстрагируясь от реальных образов, а произведения художников нередко предполагают неоднозначность прочтения. Предпосылками принципиально новой культуры мышления и новых философских основ искусства, стали на наш взгляд, нелинейная психология восприятия, концепщия иллюзии, обращение к методу интуиции и замена понятийного мышления образным мышлением.

International Culture \& Technology Studies, Vol. 3, No. 1-2 
По мнению Р. Гарифуллина [3] психическая реальность всегда была постмодернистской (нелинейной), всегда присутствовала в нашей психике, но благодаря искусству стала обособленным объектом восприятия. Так, например, эволюция кино обязана монтажу, открытому Эйзенштейном, но сами принципы уже были заложены. Монтажные принципы, когда человек соединял разрозненные впечатления в единую, целостную картину задолго до постмодернизма имели место в литературе, живописи, театре и других видах искусства.

Жизнь имеет не только чисто рационалистическую составляющую, но и некую переживаемую эмоционально-ценностную составляющую. В эпоху постмодернизма и медиакультуры, по нашему мнению, именно эта составляющая выходит на первый план. Концепция рационального человека утратила силу. Иллюзии стоят между человеком и миром. Это живые смыслы, переживание человеком своей связи с миром. Человек находится в поисках смыслов, а находит иллюзии, которые заменяют в восприятии человека смыслы, становясь целью его поиска. Иллюзия предмета позволяет находить новые смыслы, поскольку состоит в том, что каждый предмет, помимо своей естественной жизни, несет в себе потенциальную бесконечность того, чем он может стать в контексте человеческой деятельности [3] (следует добавить, не только деятельности, но и сознания вообще). Метаморфозы с реальными объектами, позволяют художникам создавать целые миры и уводить зрителя в иную художественную реальность.

При обращении к идее иллюзии предмета, на наш взгляд, становится ясна роль и необходимость цифровых технологий как инструментария для постижения «бесконечности» предмета.

\section{4. Методологические характеристики эстетики постмодернизма}

В эпоху постмодернизма в рамках литературно-художественного направления изменения выразились в поисках нового языка современного искусства. Ответом на этот поиск стал синтез реалистического и натуралистического способа воспроизведения реальности, привлечения абстракции и с сюрреалистических и символических форм. Это произошло и в других видах творческой и интеллектуальной деятельности, причем это были не только поиск новых форм и языка, но и в целом рождение новой эстетики.

В эстетике постмодернизма появляются новые черты и термины, например, симулякр, деконструкция, интертекстуальность, мозаичнсть, нониерархичность, ризома, парадоксальность, маргинальность, эстетизаиия безобразного.

Симулякр - образ отсутствующей действительности, гиперреалистический объект, за которым не стоит какая-либо реальность.

Термин «ризома» впервые появилось в книге Ж. Делёзом и Ф. Гваттари в 1976 года. Под ризомой понимаем нелинейный способ развития бытия и сознания, для которого характерно отсутствие упорядоченности, направления, синхронного порядка. Ризома должна противостоять неизменным линейным структурам, типичным для классической европейской культуры [9].

Интертекстуальность текстов означает связи, благодаря которым тексты могут различными способами явно или неявно ссылаться друг на друга. Термин был введен Ю. Кристевой в 1967 г. и сегодня употребляется не только в литературоведении, но и для определения миро- и самоощущения современного человека (постмодернистская чувствительность). Текст, понятие в сознании, другое художественное произведение представляет собой ткань, сотканную из старых цитат, обрывков культурных кодов, формул, ритмических структур, фрагментов социальных идиом и т. п. [4, с. 208-209].

Понятие деконструкиии введено в 1964 г. Ж. Лаканом под влиянием М. Хайдеггера и обосновано Ж. Дерридой. Постмодернизм ставит под вопрос само существование смысла, центральным методологическим понятием становится «деконструкция», когда выявляется внутренняя противоречивость текста, закрепленных в языке стереотипов, которые, в свою очередь, независимо от автора текста трансформируются под воздействием языковых клише его времени. 
В сравнении с эпохой Модерна, при Постмодерне масс медиа выступают не как источник информации о реальности, а является проводником симуляции информации, коммуникации, смысла, что, кстати, согласуется с такими характеристиками как маргинальность и деконструкция.

Еще одной важной характеристикой становится полистилистика, означающая взаимопроникновение различных художественных систем, уход от противопоставления «высокого» и «низкого», от разделения на элитарную и массовую культуру. Философы постмодерна (Бодрийар, Делез, Деррида, Лиотар, Фуко, Хайдеггер) доказывают условность и искусственный характер основных категорий западной рациональности, как и оспаривают существование неких общих принципов и законов, управляющих миром.

\section{5. От концептов новой философии искусства к новой картине мира изобразительного искусства}

Изменения в искусстве до цифровых технологий происходили в плоскости традиционных материалов и техник. В конце XIX в. до середины XX в. развивались различные направления, перевернувшие картину мира искусства. Представители импрессионизма стремились уловить состояние природы, естественно и живо запечатлеть реальный мир в его подвижности и изменчивости, передать свои мимолётные впечатления. Более глубокий уход в переживание, постепенный отход от предмета воплотился в экспрессионизме, когда важен не объект и образ сам по себе, а чувства и эмоции автора, вызванные объектом или его отношение к объекту, когда субъективность творческого акта превыше всего.

Полный отход от предметности воплотился в абстракционизме. В 1913 г. в рамках абстрактного искусства возникает направление, названное супрематизм (от фр. «господство», «превосходство»). Концепция «потока сознания», поклонение интуитивному началу нашли отражение в сюрреализме, получившем начало в 20-е годы XX в. Но его истоки прослеживаются в дадаизме, существовавшем в 1916-1922 гг. Главной идеей дадаизма было разрушение какой бы то ни было эстетики, полное отрицание любых смыслов. Коллаж и инсталляция, очень популярные и в настоящее время, начали применяться именно в творчестве дадаистов.

На наш взгляд, новое сознание является основой удивительных превращений в системе искусства в эпоху постмодернизма, которые, как нам кажется, начались с неудовлетворенности известными способами и методами в искусстве для отображения мира и отношения к нему человека, а вылились в многоообразие видов, в синтетические формы творческого процесса и самих произведений, сращиваясь с наукой и технологиями. Наблюдается растущая тенденция к синтетичности: сейчас художник все реже обходится возможностями одной формы для выражения видения мира и воплощения идей.

Новые принципы познания, новая эстетика, интерес к чувственным аспектам восприятия, поиск концептуальности и новые подходы к поиску смыслов выдвинули новые требования к искусству и творческой деятельности в целом. В основе же, конечно, лежала новая философия и культура общества.

\section{3. Вопросы интеграции цифровых технологий и искусства}

\section{1. Влияние технологий на культуру и искусство - индуцированный эффект}

Несмотря на предопределённость философских «поворотов» сознания и, в частности, художественного сознания, необходимо видеть «обратное» влияние, обеспечивающее индуцированный эффект технологий. Несомненно, наблюдается реакция за счет модифицирующего воздействие мира технологий на человека и культуру.

Влияние технологий и цифровой революции состоит в том, что хотя, как было отмечено, в принципах искусства отражаются психологические закономерности, в то же время, язык, принципы и алгоритмы искусства под воздействием технологий, развиваясь, постепенно стали преобразовывать сознание человека, делая его клиповым, виртуальным, компьютерным. Само это изменение сознания человека стимулировало решать задачи искусства с помощью развивающихся

International Culture \& Technology Studies, Vol. 3, No. 1-2 
цифровых технологий посредством расширения практики их применения в различных видах творческой деятельности.

В процессе развития новых форм искусств нельзя игнорировать технологическое влияние на художника как сопутствующий и одновременно самостоятельный фактор развития цифрового искусства. Новое направление в искусстве, видео-арт, появилось тогда, когда художники начали исследовать доступные им границы технологий и экспериментировать. Однако, как и всегда в искусстве, мотивом и духовным стержнем художественной деятельности оставалось переживание художником действительности и собственной жизни, его отношение к миру. Тот же принцип понимания применим и к новым цифровым видам. Психология восприятия диктует новые принципы визуализации.

\section{2. Проблема сохранения искусством своей идентичности в мире цифровых технологий}

В соответствии с новой философии и новому восприятию человеку помимо традиционных средств и методов искусства стали необходимы новые средства, новые методы и формы выражения и трансфера знания, чувств, идей, настроения, отражения эпохи.

Дискуссионным представляется вопрос о месте цифровых технологий и традиционных видов и нецифровых методов искусства. Особую проблему составляют «синтетические» произведения, где используются и традиционные методы, и технологические компьютерные средства. Например, анимация наследует те же способы создания изображений, что и до цифровых технологий. А цифровая живопись основана на компьютерных имитациях традиционных инструментов художника. Даже в трёхмерной графике и анимации 3D-модель может быть не только полностью абстрактной или вымышленной, но и реалистичной на основе реалистических изображений. Оцифровка изображений, полученных ранее традиционными методами, позволяет их использовать в таком виде искусства, как фотоманипуляция, представляющей собой соединение частей разных изображений и графических элементов с целью получить совершенно новое произведение со своим смыслом. «Графика движения» быстро развивалась благодаря программам, подобным Adobe After Effects, Maya, Autodesk 3D Studio Max, которые объединили специальные эффекты обработки видео, наборы инструментов для цветовой коррекции, текстовой анимации, движения камеры и создания многослойных композиций. В визуальном цифровом искусстве многие авторы используют целый комплекс различных цифровых инструментов и смешанные техники, создавая все более необычные образы и благодаря обновляющимся программам и высокой скорости распространения инноваций.

Следует заметить, именно с этой динамикой новаций связана трудность строгой классификации работ цифровых художников. Не существует на настоящий момент и исчерпывающей классификации искусств, так как границы между формами творческой деятельности и искусства, как ее высшей формы, размыты. Вопрос классификации и конкуренции традиционных и цифровых видов искусства - это сложный вопрос, нередко затрагиваемый исследователями, и пока не него нет однозначного ответа. Одной из причин является скорость появления новых экспериментальных произведений, сложный синтетический характер средств их производства.

Рассматривая многообразие видов искусства, нельзя не признать, что в некоторых новых видах искусства, которые динамично развиваются, и в творческом эксперименте можно найти больше науки и инженерного искусства, чем искусства в традиционном смысле этого слова. Это справедливо, например, для энвайронментализма, который, в свою очередь, был тесно связан с другими арт-практиками, в частности, ленд-артом, экологическим искусством, арте повера, биоартом, art\&science.

По нашему мнению, искусство сохраняет свою идентичность как искусство среди других видов творчества, в первую очередь тогда, когда присутствует профессионализм, сохраняется социально-гуманитарная миссия, акты творчества имеют духовную и культурную ценность, в частности художественную идею и цели, и что также важно, не противоречат гуманистическим канонам культуры. 


\section{Заключение}

Таким образом, технологии стали включаться в процессы творчества именно потому, что усложнились философские основы искусства и были поставлены новые прикладные задачи. А сознание человека подвергалось влиянию «цифрового» опыта, что в свою очередь видоизменяло культурологическую основу, философию искусства.

Опираясь на проведенный анализ, выделим основные, по нашему мнению, предпосылки и причины обусловленности включения цифровых технологий в искусство:

- Психология творчества как фактор эволюиии искусства;

- Новый метод познания и существование человека в мире технологий на всех уровнях бытия;

- Новая эстетика постмодернизма, в рамках которой происходило вовлечение ичирровых технологий в культуру и искусство,

- Новые философские основы культуры (и в частности - искусства) в пространстве медиакультуры.

Качества человека информационного общества модифицируются, и связано это в немалой степени с активным внедрением информационных технологий в процессы художественных практик.

С одной стороны, исторически и объективно философия культуры оказывала влияние на развитие новых форм и концептуальное содержание искусства, что, в свою очередь, отразилось в поиске новых средств выражения через возможности цифровых технологий. Усиление роли технологий в информационном обществе, изменения в медиакультуре и в массовом сознании, с другой стороны, оказало влияние на формы культуры и искусства и их философию.

Цифровые технологии принесли новые эффекты в процесс развития культуры и искусства. Они позволили отказаться от понимания произведения как материального объекта, при этом сохранив визуальный характер художественной коммуникации, дали возможность воплощать художникам концепцию иллюзии предмета благодаря расширению технических средств. Цифровые компьютерные технологии не только привели к новым формам искусства, но и способствовали формированию новых видов эстетики в ее разных направлениях, как например, информационная эстетика, генеративная, алгоритмическая, виртуальная, симуляционная и другие.

Если влияние технологий на философию и сознание выразилось в том, что они заставляют нас переосмысливать основополагающие положения не только эстетики, но и теории познания, то можно выделить отдельно эффекты, которые принесли технологии в отношении искусства:

- оказали влияние на художественное мышление;

- трансформировали структуру искусства;

- расширили инструментарий художника;

- определили необходимость переосмысления места самого изобразительного искусства в системе искусств.

Материальные, духовные, художественные ценности культуры дублируются в виртуальной реальности, и это ведет к более широкому доступу к информации о культурных и художественных объектах, поэтому говорить об отказе от культурного наследия культуры и искусства или замене традиционного искусства цифровым искусством представляется некорректным.

Потенциал цифровых компьютерных технологий следует рассматривать не только как путь к формированию другой конкурирующей художественной виртуальной реальности, но и как инструментарий для сохранения и обеспечения наследования и переработки художественного, исторического культурного опыта человечества.

International Culture \& Technology Studies, Vol. 3, No. 1-2 


\title{
Литература
}

[1] Балакина Е. И. Специфика определения сущности искусства в генетических концепциях XX века//Журнал «Исторические, философские, политические и юридические науки, культурология и искусствоведение. Вопросы теории и практики» 2015. № 8. Ч. 2, С.37-41

[2] Бергсон Анри. Творческая эволюция. (L'Evolution creatrice) /монография. - Пер. с фр. В. Флеровой; Вступ. ст. Блауберг И. - М.: ТЕРРА-Книжный клуб; КАНОН-пресс-Ц, 2001. — 384 с. URL: http://www.litresp.ru/chitat/ru/\%D0\%91/bergson-a/tvorcheskaya-evolyuciya (дата обращения: 5/8/2018)

[3] Гарифуллин Р. Р. Постмодернистская психология смысла. Введение в постмодернистскую (неклассическую) психологию. URL: http://www.psyfactor.org/lib/postmodern.htm

[4] Дранов А. В., Ильин И. П., Козлов А. С. и др. Современное зарубежное литературоведение. Страны Западной Европы и США. Концепции, школы, термины. М.: INTRADA, 1996. - 319 с.

[5] Ильин И. П. Постмодернизм от истоков до конца столетия: эволюция научного мифа. Москва: Интрада. 1998. URL: http://www.lib.ru/CULTURE/ILIN/postmodern.txt

[6] Кириллова Н.Б. Медиакультура: от модерна к постмодерну. М.: Академический проект, 2005. — 448 с. URL: http://www.refdb.ru/look/2037961-pall.html (дата обращения: 31/7/2018)

[7] Лавинская Л. А., Сороковикова В. И. Эпоха Постмодерна и культура постмодернизма: философский и культурологический подходы. URL: http://kilouma.ru/safia/l-a-lavinskaya-v-i-sorokovikova-epohapostmoderna-i-kuletura-p/main.html (дата обращения: 8/8/2018).

[8] Лиотар Жан-Франсуа. Состояние постмодерна/ пер. с франц. Н. А. Шматко. Институт экспериментальной социологии. Москва Издательство «Алтея», Санкт-Петербург, 1998, 160 с. URL: http://www.rebels-library.org/files/liotar_sostajanie_postmoderna.pdf

[9] Сайт «Викепедия» URL: http://www.ru.wikipedia.Ризома

[10] Флоренский П. А. Собрание сочинений. Философия культа (Опыт православной антроподицеи). М.: Мысль, 2003. 685 с.

[11]Хренов Н. А. Социальная психология искусства: переходная эпоха. - М.: Альфа-М., 2005. - 624 с.

\section{The Digital Evolution of Art: Sociocultural Analysis in the Context of Philosophy and Postmodern Culture}

\author{
L.A. Koroleva
}

Herzen State Pedagogical University of Russia, Russia

\begin{abstract}
The paper conducts an analysis of the prerequisites and relationships in the processes of integrating digital technologies into art. The article reveals evidence that both the necessity of using digital technologies and the development of innovative "digital" forms of art are due, first, to the very nature of creativity, and secondly, to the changing psychology of cognition and the person's consciousness. The paper suggests an integrated approach to the analysis of new forms of modern visual art, based on the study of impact of Digital technologies and changes in postmodernizm philosophy and culture. The author suggests examining the problem of the competition of traditional and digital art and the synthesis of digital technologies and traditional methods in art from the standpoint of understanding postmodernism as a state of the spiritual culture of a modern postindustrial society.
\end{abstract}

Keywords: digital technologies, postmodern, aesthetics of postmodernism, media culture, non-linear psychology of consciousness, the concept of illusion, the philosophical foundations of art

\section{References}

[1] Balakina E. I. (2015) Specifika opredeleniya sushchnosti iskusstva v geneticheskih koncepciyah HKH veka//ZHurnal «Istoricheskie, filosofskie, politicheskie i yuridicheskie nauki, kul'turologiya i iskusstvovedenie. Voprosy teorii i praktiki» No.8. P. 2. 37-41

[2] Bergson Anri. (2001)Tvorcheskaya ehvolyuciya. (L'Evolution creatrice) /monografiya. - Per. s fr. V. Flerovoj; Vstup. st. I. Blauberg. - M.: TERRA-Knizhnyj klub; KANON-press-C.384 p. URL: http://www.litresp.ru/chitat/ru/\%D0\%91/bergson-a/tvorcheskaya-evolyuciya/ (accessed date: 5/8/2018).

[3] Garifullin R.P. Postmodernistskaya psihologiya smysla. Vvedenie v postmodernistskuyu (neklassicheskuyu) psihologiyu. URL: http://www.psyfactor.org/lib/postmodern.htm/(accessed date: 1/8/2018). 
[4] Dranov A.V., Il'in I.P., Kozlov A.S. i dr. (1996) Sovremennoe zarubezhnoe literaturovedenie. Strany Zapadnoj Evropy i SSHA. Koncepcii, shkoly, terminy. M.: INTRADA. 319 p.

[5] Il'in I.P. (1998) Postmodernizm ot istokov do konca stoletiya:ehvolyuciya nauchnogo mifa. Moskva: Intrada.. URL: http://www.lib.ru/CULTURE/ILIN/postmodern.txt

[6] Kirillova N.B. (2005) Mediakul'tura: ot moderna k postmodernu. M.: Akademicheskij proekt. 448 p. URL: http://www.refdb.ru/look/2037961-pall.html (accessed date: 31/7/2018).

[7] Lavinskaya, V.I. Sorokovikova. Ehpoha Postmoderna i kul'tura postmodernizma: filosofskij i kul'turologicheskij podhody. URL: http://kilouma.ru/safia/l-a-lavinskaya-v-i-sorokovikova-epoha-postmodernai-kuletura-p/main.html

[8] Liotar Zhan-Fransua. (1998) Sostoyanie postmoderna/ per. s franc. N.A.SHmatko. Institut ehksperimental'noj sociologii. Moskva Izdatelstvo «Alteya», Sankt-Peterburg. 160 p. URL: http://www.rebelslibrary.org/files/liotar_sostajanie_postmoderna.pdf/(accessed date: 8/8/2018).

[9] Sajt «Vikepediya» URL: http://www.ru.wikipedia.Rizoma /(accessed date: 20/7/2018).

[10] Florenskij P.A. (2003) Sobranie sochinenij. Filosofiya kul'ta (Opyt pravoslavnoj antropodicei). M.: Mysl. 685 p.

[11]Hrenov N. A. (2005). Social'naya psihologiya iskusstva: perekhodnaya ehpoha. - M.: Alfa-M. 624 p. 